\title{
The Assessment of Risk Factors for Development of Disability in Children with Congenital Hypothyroidism in Uzbekistan within a Neonatal Screening
}

\author{
Gulnara N. Rakhimova ${ }^{1^{*}}, \mathrm{PhD}, \mathrm{ScD}$; Gulshad M. Zhiemuratova ${ }^{2}$; Anna V. Aliyeva ${ }^{3}, \mathrm{PhD}$ \\ ${ }^{1}$ Tashkent Institute of Postgraduate Medical Education, Tashkent, Uzbekistan \\ ${ }^{2}$ Endocrinological dispensary of the Republic of Karakalpakstan, \\ Nukus, Republic of Karakalpakstan, Uzbekistan \\ ${ }^{3}$ Republican Specialized Scientific-Practical Medical Centre of Endocrinology named after \\ Academician Ya. Kh. Turakulov, Tashkent, Uzbekistan
}

\begin{abstract}
The aim of this study was to detect the most significant risk factors leading to disability in children with congenital hypothyroidism $(\mathrm{CH})$ in the autonomous Republic of Karakalpakstan (RK) during neonatal screening (NS).

Methods and Results: We used data of patients with CH registered within NS in the RK in 1998-2019 by the Center for Screening of Mother and Child. To predict and calculate the most significant risk factors for disability in children with $\mathrm{CH}$, we used the method of normalizing intensive indicators by E. Shigan, based on the Bayes theorem.

The study recruited 111 patients with $\mathrm{CH}$ aged from 2 months to 20 years. Among the patients, there were 79(71.2\%) girls and $32(28.8 \%)$ boys. Additionally, 34(30.6\%) children with $\mathrm{CH}$ had been disabled since childhood. The lack of compensation after the start of treatment had the highest and most significant degree of disability risk ( $R R=6.39,95 \% \mathrm{CI}$ : 7.4-1.2). Among patients diagnosed outside of screening, disability developed 4.1 times more often than with the results of NS (RR=4.0,95\% CI: 1.1-10.6). In CH patients diagnosed outside of screening, "absence of reagents" was a significant factor increasing the risk of disability by 6.1 times (RR=6.1, 95\% CI: 1.8-11.2). Such risk factors as "home delivery" and "parental refusal of the primary test" increased the risk of disability by 3.4 times $(\mathrm{RR}=3.4,95 \% \mathrm{CI}: 2.5-8.4)$ and 1.6 times $(\mathrm{RR}=2.4,95 \% \mathrm{CI}: 2.93-7.12)$, respectively. The possible errors or false-negative answers in the "normal" secondary test and the "normal" primary test increased the risk of disability by 3.3 times (RR=4.0, 95\% CI: 3.2-10.7) and 2.4 times ( $R R=2.42,95 \%$ CI: 2.93-7.12), respectively. Factors such as the "late response to retesting" ( $R R=0.8295 \%$ CI: 0.65-0.54), "late awareness on the part of the medical staff" ( $R R=0.29,95 \%$ CI: 0.27- 0.08), and "parental refusal of treatment" $(\mathrm{RR}=1.03,95 \% \mathrm{CI}: 0.81-0.84)$ showed less significance in patients' disability. The "starting treatment after 1 month" factor was 4.2 times more likely to result in disability than "starting treatment before 1 month" (RR=4.2, 95\% CI: 4.5 -1.1). Cancellation of levothyroxine by parents for children up to 3 years of age and cancellation of treatment by parents after 3 years more likely resulted in disability by 1.4 times $(\mathrm{RR}=1.43,95 \% \mathrm{CI}: 1.4-2.01)$ and 3.3 times ( $\mathrm{RR}=3.33,95 \% \mathrm{CI}$ : 3.3-10.9), respectively.

Conclusion: the most significant risk factors for the development of disability in children with $\mathrm{CH}$ in the RK were (in descending order): no compensation after starting treatment, no reagents for screening, starting treatment after 1 year, diagnostics outside of screening, cancellation of L-T4 by parents before and after age 3 years, false-negative secondary TSH test, false-negative primary test, parents refusing the primary test, and childbirth at home.(International Journal of Biomedicine. 2021;11(3):265-270.)
\end{abstract}

Key Words: risk factors $\bullet$ congenital hypothyroidism $\bullet$ disability $\bullet$ neonatal screening

For citation: Rakhimova GN, Zhiemuratova GM, Aliyeva AV. The Assessment of Risk Factors for Development of Disability in Children with Congenital Hypothyroidism in Uzbekistan within a Neonatal Screening. International Journal of Biomedicine. 2021;11(3):265-270. doi:10.21103/Article11(3)_OA2

\section{Abbreviations}

CH, congenital hypothyroidism; CH-C, congenital central hypothyroidism; NII, normalized intensive indicator; NS, neonatal screening; THs, thyroid hormones; TSH, thyroid stimulating hormone. 


\section{Introduction}

Primary congenital hypothyroidism $(\mathrm{CH})$ is a congenital deficiency of thyroid hormones (THs) in newborns, resulting from incomplete development of the thyroid gland in ontogenesis or from disorder of synthesis and secretion of thyroid hormones, which leads to a lag in the development of all organs and systems of the body, and especially to severe mental retardation and delayed physical development. ${ }^{(1-4)}$ THs are essential for normal growth and development of the central nervous system, especially in the first 3 years of life..$^{(5)}$ During the period of rapid growth and active neurogenesis, the brain becomes especially sensitive to deficiency of thyroxine. Therefore, thyroid failure delays the development of the brain and its maturation, leading to irreversible mental retardation. ${ }^{(1)}$

The prevalence of $\mathrm{CH}$ varies significantly in different countries of the world and ranges from 1 to 2000 to 1 to 3000 newborns. The incidence of $\mathrm{CH}$ varies significantly among different ethnic groups and geographic locations, depends on the severity of iodine deficiency in the country, and occurs 2-2.5 times more often in girls than in boys..$^{(1,6-8)}$

In the mid-70s, many developed countries introduced the state system of NS for $\mathrm{CH}$ because of a high incidence of $\mathrm{CH}$, as well as serious consequences and late diagnosis. $(9,10)$ Mass screening was first carried out in Canada in 1974, and today this method is used in the majority of developed countries. ${ }^{(11)}$

The organization of NS for CH in Uzbekistan is carried out in accordance with the Resolution of the Cabinet of Ministers of the Republic of Uzbekistan, dated 01.04.1998, "On the creation of the State system for early detection of congenital and other pathologies in newborns and pregnant women to prevent the birth of disabled people." A modern screening center was organized in the autonomous Republic of Karakalpakstan (RK) in 1997.(12) Modern screening centers are organized in each region. Diagnostics, treatment, and monitoring of patients with $\mathrm{CH}$ aged up to 18 years is carried out free of charge under the supervision of screening centers.

Among the studied risk factors affecting mental and physical development, the most important are: 1) the first therapeutic dose, 2) the age treatment is initiated, 3) the age thyroxine levels are normalized. ${ }^{(13)}$ The latest Guidelines of the European Society for Pediatric Endocrinilogy 2020-2021 confirm that after a newborn receives a positive result of screening for $\mathrm{CH}$, immediate administration of levothyroxine in the first 2 weeks at a dose of $10-15 \mu \mathrm{g} / \mathrm{kg}$ per day is the most optimal. ${ }^{(8)}$

Despite the development of more accurate test programs, approximately $5 \%$ of cases of $\mathrm{CH}$ can still be missed in any screening program. Causes may be loss of sample collection, poor samples, misinterpretation of results, subclinical hypothyroidism, or, if TSH is measured alone, failure to detect infants with $\mathrm{CH}-\mathrm{C}$. ${ }^{(14)}$

Any screening system turns into large financial costs for the state. For this reason, any screening system requires periodic evaluation of its effectiveness. In the RK, among 111 patients with $\mathrm{CH}, 34$ are disabled. Therefore, it became necessary to assess the effectiveness of NS in the RK. There were no similar studies in Uzbekistan.

The aim of this study was to detect the most significant risk factors leading to disability in children with $\mathrm{CH}$ in the $\mathrm{RK}$ during NS.

\section{Materials and Methods}

We used data of patients with $\mathrm{CH}$ registered within NS in the RK in 1998-2019 by the Center for Screening of Mother and Child. The results of NS for $\mathrm{CH}$ were evaluated according to the level of TSH in capillary blood, collected on filter paper from newborns 4-5 days after birth. Testing for THs (TSH, total T4, and total T3) was carried out in the NS laboratory using the DELFIA multifunctional automated immunological laboratory, consisting of a Wallas VICTOR-2D analyzer and a set of auxiliary equipment.

The time for prescribing treatment after birth, the thyroxine dose, and the achievement of the target TSH levels were assessed on the basis of the ESPE recommendations. ${ }^{(3)}$

To predict and calculate the most significant risk factors for disability in children with $\mathrm{CH}$, we used the method of normalizing intensive indicators by E. Shigan, based on the Bayes theorem. ${ }^{(15)}$

Based on the literature data, the following risk factors were identified and were included in the analysis: the time of diagnosis during screening, diagnostics outside the screening, the timing treatment was initiated (up to 1 month or after 1 month), compensation after the start of treatment, correctly selected dosage of levothyroxine directly at diagnosis, refusal of treatment by parents, lack of reagents for screening, parents' refusal of primary testing, the rate of "normal" primary test, the rate of "normal" retest, late informing of parents about retesting by medical personnel, late parental response to retesting, childbirth at home, and cancellation of treatment by parents (under age 3 and over age 3 ).

The NII was calculated for the gradation of each factor, that is, the frequency of cases of disability, according to this gradation, was divided by the total frequency of disability in the surveyed population (30.6\%). In order to determine how many times the presence of a factor increases the risk of developing disability, the relative risk index (RR) was calculated. The indicators of RR were also determined according to the gradation of each factor. After determining the NII and RR, for a comprehensive assessment of the phenomenon under study, the corresponding NII values were multiplied by the $\mathrm{RR}$ indicators. That is, the integral assessment was determined by the formula: $\mathrm{X}=\mathrm{NII} \times \mathrm{RR}$, where $\mathrm{X}$ is the integral risk assessment.

Statistical analysis was performed using Microsoft Excel software package. The normality of distribution of continuous variables was tested by one-sample KolmogorovSmirnov test. Baseline characteristics were summarized as frequencies and percentages for categorical variables and as mean \pm standard deviation (SD) for continuous variables. For data with normal distribution, inter-group comparisons were performed using Student's t-test. A probability value of $\mathrm{P}<0.05$ was considered statistically significant. 


\section{Results}

The study recruited 111 patients with $\mathrm{CH}$ aged from 2 months to 20 years. Among the patients, there were $79(71.2 \%)$ girls and 32(28.8\%) boys. Additionally, 34(30.6\%) children with $\mathrm{CH}$ had been disabled since childhood, of which 6(17.6\%) had a normal TSH level at Stages 1-2 of screening (the socalled "missed" results), 18(52.9\%) children were identified outside of screening, and 10(29.5\%) during the screening.

During NS of 87 newborns, disability since childhood was diagnosed in $16(18.4 \%)$ of patients. Among 24 children outside NS, disability since childhood was diagnosed in $18(75 \%)$. Several factors have been identified that affect the CH diagnosis (Table 1).

Table 1.

Frequency of some risk factors in children with $\mathrm{CH}$ and disability

\begin{tabular}{|c|c|c|c|}
\hline & \multirow{2}{*}{$\mathrm{n}$} & \multicolumn{2}{|c|}{ Disability } \\
\hline & & $\mathrm{n}=34$ & $\%$ \\
\hline Frequency of disability within NS & 87 & 16 & 18.4 \\
\hline Frequency of disability outside NS & 24 & 18 & 75 \\
\hline \multicolumn{4}{|c|}{$\underline{\text { Risk factors for } \mathrm{CH} \text { during NS}}$} \\
\hline & $\mathrm{N}$ & $\mathrm{n}=13$ & $\%$ \\
\hline Late response to retesting & 15 & 4 & 26.7 \\
\hline $\begin{array}{l}\text { Late awareness on the part of the medical } \\
\text { staff }\end{array}$ & 18 & 2 & 11.1 \\
\hline "normal" primary test & 9 & 6 & 66.7 \\
\hline "normal" secondary test & 1 & 1 & 100 \\
\hline \multicolumn{4}{|c|}{$\underline{\text { Risk factors for disability and late diagnosis of } \mathrm{CH} \text { (outside NS) }}$} \\
\hline & $\mathrm{N}$ & $\mathrm{n}=18$ & $\%$ \\
\hline Home delivery & 2 & 2 & 100 \\
\hline Absence of reagents & 20 & 15 & 75 \\
\hline Parental refusal of the primary test & 2 & 1 & 50 \\
\hline \multicolumn{4}{|c|}{$\underline{\text { Risk factors for disability depending on treatment }}$} \\
\hline & $\mathrm{N}$ & $\mathrm{n}=8$ & $\%$ \\
\hline $\begin{array}{l}\text { Early onset of treatment (within } 1 \\
\text { month) }\end{array}$ & 40 & 4 & 10 \\
\hline $\begin{array}{l}\text { Compensation after the onset of } \\
\text { treatment }\end{array}$ & 18 & 1 & 5.6 \\
\hline $\begin{array}{l}\text { Decompensation after the onset of } \\
\text { treatment }\end{array}$ & 22 & 3 & 35.5 \\
\hline \multicolumn{4}{|c|}{ Early onset of treatment (within 1 month) } \\
\hline & $\mathrm{N}$ & $\mathrm{n}=4$ & $\%$ \\
\hline $\begin{array}{l}\text { Cancellation of treatment by parents } \\
\text { (before age of } 3 \text { years) }\end{array}$ & 7 & 3 & 42.9 \\
\hline $\begin{array}{l}\text { Cancellation of treatment by parents } \\
\text { (after age } 3 \text { years) }\end{array}$ & 1 & 1 & 100 \\
\hline
\end{tabular}

During the neonatal period, additional risk factors were identified in $\mathrm{CH}$ children, affecting treatment and leading to the disability (Table 1). Among patients diagnosed outside of screening, disability developed 4.1 times more often than with the results of NS ( $R=4.0,95 \% \mathrm{CI}: 1.1-10.6)$. In $\mathrm{CH}$ patients diagnosed outside of screening, "absence of reagents" was a significant factor increasing the risk of disability by 6.1 times $(\mathrm{RR}=6.1,95 \% \mathrm{CI}: 1.8-11.2)$. Such risk factors as "home delivery" and "parental refusal of the primary test" increased the risk of disability by 3.4 times $(\mathrm{RR}=3.4,95 \% \mathrm{CI}: 2.5-8.4)$ and 1.6 times $(\mathrm{RR}=2.4,95 \% \mathrm{CI}$ : 2.93-7.12), respectively.

The possible errors or false-negative answers in the "normal" secondary test and the "normal" primary test increased the risk of disability by 3.3 times $(\mathrm{RR}=4.0,95 \%$ CI: 3.2-10.7) and 2.4 times ( $R R=2.42,95 \%$ CI: 2.93-7.12), respectively. Factors such as the "late response to retesting" ( $R R=0.82$ 95\% CI: 0.65-0.54), "late awareness on the part of the medical staff" ( $R R=0.29,95 \%$ CI: 0.27- 0.08), and "parental refusal of treatment" $(\mathrm{RR}=1.03,95 \% \mathrm{CI}$ : 0.81-0.84) showed less significance in patients' disability (Table 2).

The "starting treatment after 1 month" factor was 4.2 times more likely to result in disability than "starting treatment before 1 month" ( $\mathrm{RR}=4.2,95 \% \mathrm{CI}: 4.5-1.1)$. Cancellation of levothyroxine by parents for children up to 3 years of age and cancellation of treatment by parents after 3 years more likely resulted in disability by 1.4 times $(\mathrm{RR}=1.43,95 \% \mathrm{CI}: 1.4-2.01)$ and 3.3 times $(\mathrm{RR}=3.33,95 \%$ CI: 3.3-10.9), respectively. The lack of compensation after the start of treatment had the highest and most significant degree of disability risk ( $\mathrm{RR}=6.39,95 \%$ CI: 7.4-1.2) (Fig.1).

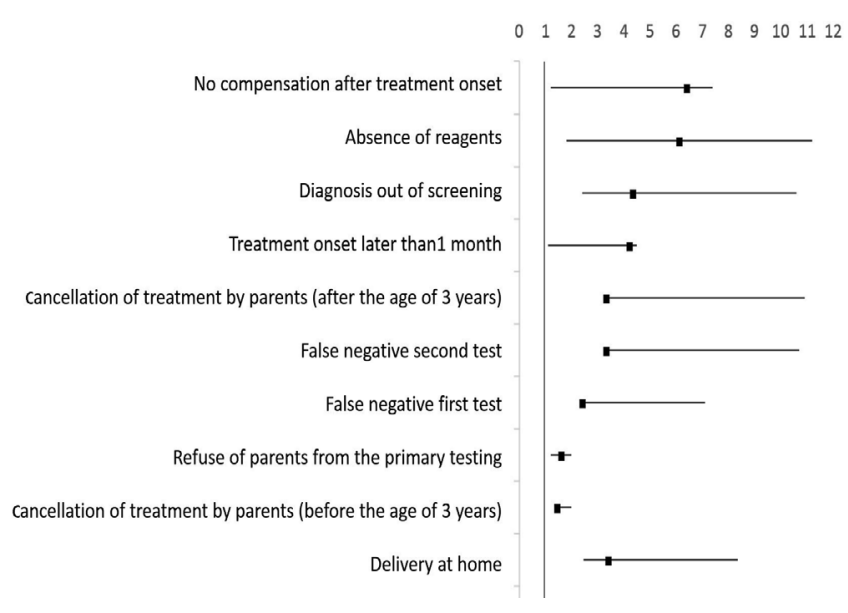

Fig.1. The most significant risk factors for the development of disability among children with $\mathrm{CH}$

When assessing thyroid function, out of 40 patients with an early start of treatment with levothyroxine, only $18(45 \%)$ children were compensated and $22(55 \%)$ patients were decompensated $(\mathrm{TSH}>5 \mu \mathrm{U} / \mathrm{ml})$. The data obtained confirm that a significant proportion of patients with $\mathrm{CH}$ were decompensated (Table 3). 
Table 2.

Integral analysis of risk factors for the development of disability among children with $\mathrm{CH}$

\begin{tabular}{|c|c|c|c|c|c|}
\hline Risk factor & $\begin{array}{l}\text { Gradation } \\
\text { of factors }\end{array}$ & $\begin{array}{c}\text { Disability, } \\
\%\end{array}$ & NII & $\mathrm{RR}$ & $\mathrm{X}$ \\
\hline \multirow{2}{*}{$\begin{array}{l}\text { Decompensation } \\
\text { after the onset of } \\
\text { treatment }\end{array}$} & No & 5.555556 & 0.1815541 & \multirow{2}{*}{6.4} & 1.1596036 \\
\hline & Yes & 35.483871 & 1.1596036 & & 7.4065006 \\
\hline \multirow{2}{*}{$\begin{array}{l}\text { Absence of } \\
\text { reagents }\end{array}$} & Yes & 75 & 1.8382353 & \multirow{2}{*}{6.1} & 11.226366 \\
\hline & No & 12.280702 & 0.3009976 & & 1.8382353 \\
\hline \multirow{2}{*}{ Diagnosis } & NS & 18.441379 & 0.5634438 & \multirow{2}{*}{4.0} & 2.4397115 \\
\hline & Out of NS & 75 & 2.4509804 & & 10.612745 \\
\hline \multirow{2}{*}{ Onset of treatment } & $\begin{array}{l}\text { Within } 1 \\
\text { month }\end{array}$ & 10 & 0.3267974 & \multirow{2}{*}{4.2} & 1.0686275 \\
\hline & Later & 42.253521 & 1.380834 & & 4.5153273 \\
\hline \multirow{2}{*}{$\begin{array}{l}\text { Cancellation of } \\
\text { treatment by parents } \\
\text { (after age } 3 \text { years) }\end{array}$} & Yes & 100 & 3.2679739 & \multirow{2}{*}{93.3} & 10.893246 \\
\hline & No & 30 & 0.9803922 & & 3.2679739 \\
\hline \multirow{2}{*}{$\begin{array}{l}\text { "normal" } \\
\text { secondary test }\end{array}$} & Yes & 100 & 3.2679739 & \multirow{2}{*}{3.3} & 10.686275 \\
\hline & No & 30 & 0.9803922 & & 3.2058824 \\
\hline \multirow{2}{*}{$\begin{array}{l}\text { "normal" } \\
\text { primary test }\end{array}$} & Yes & 66.666667 & 2.1786492 & \multirow[b]{2}{*}{2.4} & 7.124183 \\
\hline & No & 27.45098 & 0.8970909 & & 2.9334871 \\
\hline \multirow{2}{*}{$\begin{array}{l}\text { Parental refusal of } \\
\text { the primary test }\end{array}$} & Yes & 50 & 1.2254902 & \multirow{2}{*}{1.6} & 1.9980818 \\
\hline & No & 30.666667 & 0.751634 & & 1.2254902 \\
\hline \multirow{2}{*}{$\begin{array}{l}\text { Cancellation of } \\
\text { treatment by parents } \\
\text { (before age } 3 \text { years) }\end{array}$} & Yes & 42.857143 & 1.4005602 & \multirow{2}{*}{1.4} & 2.0137087 \\
\hline & No & 29.807692 & 0.9741076 & & 1.4005602 \\
\hline \multicolumn{6}{|c|}{ Factors of late onset of treatment $(40.8 \%)$} \\
\hline \multirow{2}{*}{ Home delivery } & Yes & 100 & 2.4509804 & \multirow{2}{*}{43.4} & 8.355615 \\
\hline & No & 29.333333 & 0.7189542 & & 2.4509804 \\
\hline \multirow{2}{*}{$\begin{array}{l}\text { Parental refusal of } \\
\text { treatment }\end{array}$} & Yes & 33.333333 & 0.8169935 & \multirow{2}{*}{1.0} & 0.8417508 \\
\hline & No & 32.352941 & 0.7929642 & & 0.8169935 \\
\hline \multirow{2}{*}{$\begin{array}{l}\text { Late response to } \\
\text { retesting }\end{array}$} & Yes & 26.666667 & 0.6535948 & \multirow{2}{*}{1.2} & 0.79064 \\
\hline & No & 32.258065 & 0.7906388 & & 0.95642 \\
\hline \multirow{2}{*}{$\begin{array}{l}\text { No assessment of } \\
\text { thyroid function } \\
\text { after age } 3 \text { years }\end{array}$} & Yes & 25 & 0.6127451 & \multirow{2}{*}{1.3} & 0.83241 \\
\hline & Assessed & 33.962264 & 0.8324084 & & 1.13082 \\
\hline \multirow{2}{*}{$\begin{array}{l}\text { No assessment of } \\
\text { thyroid function } \\
\text { before age } 3 \text { years }\end{array}$} & Yes & 14.285714 & 0.3501401 & \multirow{2}{*}{2.3} & 0.80532 \\
\hline & Assessed & 32.857143 & 0.8053221 & & 1.85224 \\
\hline & Yes & 15 & 0.3676471 & & 0.90299 \\
\hline ultrasound & Done & 36.842105 & 0.9029928 & & 2.21788 \\
\hline Late awareness & Yes & 11.111111 & 0.2723312 & & 0.91392 \\
\hline medical staff & No & 37.288136 & 0.9139249 & & 3.06707 \\
\hline
\end{tabular}

Table 3.

TSH level and thyroxine dose depending on the achievement of compensation in children with starting treatment before 1 month

\begin{tabular}{|l|c|c|c|}
\hline & $\begin{array}{c}\text { Compensation } \\
\text { after the onset of } \\
\text { treatment } \\
(\mathrm{n}=18)\end{array}$ & $\begin{array}{c}\text { Decompensation } \\
\text { after the onset of } \\
\text { treatment } \\
(\mathrm{n}=22)\end{array}$ & $P$-value \\
\hline $\begin{array}{l}\mathrm{TSH} \text { before treatment, } \\
\mu \mathrm{U} / \mathrm{ml}\end{array}$ & $150.9 \pm 44.2$ & $200.5 \pm 37.5$ & $<0.05$ \\
\hline $\begin{array}{l}\mathrm{TSH} \text { after treatment } \\
\text { onset, } \mu \mathrm{U} / \mathrm{ml}\end{array}$ & $1.6 \pm 0.4$ & $47.9 \pm 12.1$ & $<0.05$ \\
\hline $\begin{array}{l}\text { Levothyroxine dose, } \\
\mu \mathrm{g} / \mathrm{day}\end{array}$ & $35 \pm 3.1$ & $29.3 \pm 2.0$ & $>0.05$ \\
\hline $\begin{array}{l}\text { Levothyroxine dose, } \\
\mu \mathrm{g} / \mathrm{kg} / \text { day }\end{array}$ & $9.3 \pm 0.9$ & $7.3 \pm 0.4$ & $<0.05$ \\
\hline
\end{tabular}

In patients with congenital hypothyroidism in a state of compensation, the TSH level after the start of treatment was $1.6 \pm 0.4 \mu \mathrm{U} / \mathrm{ml}$ vs. $47.9 \pm 12.1 \mu \mathrm{U} / \mathrm{ml}$ in decompensation state $(P<0.05)$. In patients with compensation, the prescribed dose of levothyroxine was $9.3 \pm 0.9 \mu \mathrm{g} / \mathrm{kg}$ vs. $7.3 \pm 0.4 \mu \mathrm{g} / \mathrm{kg}$ in patients with decompensation $(P<0.05)$. It should be noted that in most newborns with congenital hypothyroidism, the prescribed doses of levothyroxine were significantly lower than those recommended by ESPE. ${ }^{(9)}$ In addition, in the first months of life, compensation was assessed based on the total level of $\mathrm{T} 4$ only in $22.5 \%$ of cases. The lack of compensation after the start of treatment increased the risk of disability in children with congenital hypothyroidism by 6.4 times.

\section{Discussion}

In Uzbekistan, according to the results of screening from 1998 to 2017, 5,820,457 newborns were tested, and congenital hypothyroidism was diagnosed in 2323 cases. ${ }^{(16)}$ In the Republic of Karakalpakstan for the period from 2003 to 2019, 383,018 newborns were examined and 124 patients were diagnosed with congenital hypothyroidism. In 2003-2019, the population frequency of congenital hypothyroidism in the Republic of Karakalpakstan, according to the results of neonatal screening, was 1:3089 newborns. Of the children with congenital hypothyroidism, $8(9.9 \%)$ were referred to the supervision of an endocrinological dispensary, $1.2 \%$ of parents refused treatment, $4(4.9 \%)$ moved, and 3 children died $(3.7 \%){ }^{(17)}$

Our study found that girls are more likely than boys to have a congenital hypothyroidism, with a ratio of 2.5:1. According to research by Yang et al., ${ }^{(18)}$ congenital hypothyroidism was also more prevalent in girls than in boys, but the reason is still unclear. ${ }^{(19)}$

We identified repeated cases of congenital hypothyroidism in 2 families (3.6\%), which coincides with the literature data. According to I.I. Dedov, ${ }^{(1)} 85 \%$ of congenital hypothyroidism cases are sporadic, and the remaining $15 \%$ of cases are caused by dyshormonogenesis.

In the Republic of Karakalpakstan from 2003 to 2019, the annual neonatal screening for congenital hypothyroidismwas an average of $60.6 \%$. The lack of full screening coverage 
was mainly due to irregular laboratory testing. For example, due to the lack of reagents, screening was not carried out in 2004 for 1 year. During this period of time, the pediatric endocrinologists and neuropathologists annually diagnosed 2-3 cases of congenital hypothyroidism based on the typical symptoms of the disease. The absence of reagents increased the risk of patients with congenital hypothyroidism developing a disability by 6.1 times, which is consistent with a study by Alimova et al. ${ }^{(20)}$

Thus, within neonatal screening, 78 patients were diagnosed with congenital hypothyroidism, and in 9 patients the diagnosis of congenital hypothyroidism was not confirmed in Stage 1, due to the low TSH levels, but the clinical signs appeared later together with high TSH levels. Thus, during the screening, $10.3 \%$ of children were missed; this is somewhat higher than in a study by A. Büyükgebiz, ${ }^{(14)}$ who found that $5 \%$ of children with congenital hypothyroidism might still be missed in any screening program.

During the screening, it was revealed that the time needed to make the diagnosis and prescribe treatment in 78 newborns with congenital hypothyroidism was 1.5 months, on average $46.2 \pm 12.4$ days after birth with fluctuations from 10 to 207 days, although according to the ESPE recommendations, testing should be done within 2 weeks. ${ }^{(9)}$ This discrepancy is explained by the large distances in the RK between populated areas, cities, and regional centers, so it takes more time to deliver blood samples from maternity hospitals to the screening center. It is proposed to solve these problems by allocating financing to maternity hospitals for postage. Similar problems were identified in a study by Kasatkina et al. ${ }^{(16)}$

Multivariate analysis confirmed that neonatal screening for congenital hypothyroidism is effective. Outside of screening, disability for congenital hypothyroidism was 4 times higher than during screening. It is necessary to strive for an early start of treatment in the first month of life and use the dose of levothyroxine according to the level of free or total T4 until TSH normalizes. The prescribed first doses of levothyroxine should correspond to international recommendations - $10-15 \mu \mathrm{g} / \mathrm{kg}$ of body weight.

Thus, the most significant risk factors for the development of disability in children with congenital hypothyroidism in the Republic of Karakalpakstan were (in descending order): no compensation after starting treatment, no reagents for screening, starting treatment after 1 year, diagnostics outside of screening, cancellation of L-T4 by parents before and after age 3 years, false-negative secondary TSH test, false-negative primary test, parents refusing the primary test, and childbirth at home.

\section{Competing Interests}

The authors declare that they have no competing interests.

\section{References}

1. Dedov II, Peterkova VA. Federal clinical guidelines (protocols) for the management of children with endocrine diseases. M., "Praktika," 2014. [In Russian].

2. Chikulaeva OA. [The Federal Clinical Recommendations on Diagnostics and Treatment of Congenital Hypothyroidism in the Children]. Problemy Endokrinologii. 2014;60(6):53-66. [Article in Russian].

3. Léger J, Olivieri A, Donaldson M, Torresani T, Krude $\mathrm{H}$, van Vliet $\mathrm{G}$, Polak M, Butler G; ESPE-PES-SLEPJSPE-APEG-APPES-ISPAE; Congenital Hypothyroidism Consensus Conference Group. European Society for Paediatric Endocrinology consensus guidelines on screening, diagnosis, and management of congenital hypothyroidism. J Clin Endocrinol Metab. 2014 Feb;99(2):363-84. doi: 10.1210/ jc.2013-1891.

4. Kopel J. A global perspective on newborn congenital hypothyroidism screening. Proc (Bayl Univ Med Cent). 2019 Oct 17;33(1):137-139. doi: 10.1080/08998280.2019.1668715. 5. Sedassari Ade A, de Souza LR, Sedassari Nde A, Borges Mde F, Palhares HM, de Andrade Neto GB. Sonographic evaluation of children with congenital hypothyroidism. Radiol Bras. 2015 Jul-Aug;48(4):220-4. doi: 10.1590/01003984.2014.0040.

6. Ismailov S.I. Iodine deficiency in Uzbekistan. Guide. Tashkent, 2016. [In Russian].

7. Dayal D, Prasad R. Congenital hypothyroidism: current perspectives. Research and Reports in Endocrine Disorders. 2015;5:91-102. doi: 10.2147/RRED.S56402.

8. van Trotsenburg P, Stoupa A, Léger J, Rohrer T, Peters C, Fugazzola L, Cassio A, Heinrichs C, Beauloye V, Pohlenz J, Rodien P, Coutant R, Szinnai G, Murray P, Bartés B, Luton D, Salerno M, de Sanctis L, Vigone M, Krude H, Persani L, Polak M. Congenital Hypothyroidism: A 20202021 Consensus Guidelines Update-An ENDO-European Reference Network Initiative Endorsed by the European Society for Pediatric Endocrinology and the European Society for Endocrinology. Thyroid. 2021 Mar;31(3):387-419. doi: $10.1089 /$ thy.2020.0333.

9. Kanike N, Davis A, Shekhawat PS. Transient hypothyroidism in the newborn: to treat or not to treat. Transl Pediatr. 2017 Oct;6(4):349-358. doi: 10.21037/ tp.2017.09.07.

10. Lain S, Trumpff C, Grosse SD, Olivieri A, Van Vliet G. Are lower TSH cutoffs in neonatal screening for congenital hypothyroidism warranted? Eur J Endocrinol. 2017 Nov;177(5):D1-D12. doi: 10.1530/EJE-17-0107.

11. Dedov II, Bezlepkina OB, Vadina TA, Baibarina EN, Chumakova OV, Karavaeva LV, Bezlepkin AS, Peterkova VA. [Screening for congenital hypothyroidism in the Russian Federation]. Problemy Endokrinologii. 2018;64(1):14-20. [Article in Russian].

12. Rakhimova G.N., Zhiemuratova G.M. [Optimization of management and treatment of congenital hypothyroidism on the example of the Republic of Karakalpakstan]. Zhurnal Teoreticheskoi i Klinicheskoi Meditsiny. 2019;(3):89-94. [Article in Russian].

13. Heidari Z, Feizi A, Hashemipour M, Kelishadi R, Amini M. Growth development in children with congenital hypothyroidism: the effect of screening and treatment

*Corresponding author: Prof. Gulnara N. Rakhimova, the Head of the Department of Endocrinology, Tashkent Institute of Postgraduate Medical Education, Tashkent, Uzbekistan. E-mail: diabetgulnora@hotmail.com. 
variables-a comprehensive longitudinal study. Endocrine. 2016 Nov;54(2):448-459. doi: 10.1007/s12020-016-1010-x. 14. Büyükgebiz A. Newborn screening for congenital hypothyroidism. J Clin Res Pediatr Endocrinol. 2013;5 Suppl 1(Suppl 1):8-12. doi: 10.4274/jcrpe.845.

15. Shigan EN. Methods of forecasting and modeling in social and hygienic research. M., "Meditsina," 1986. [In Russian]. 16. Kasatkina EP, Shilin DE, Osmanova EI, Baykov AD, Andreichenko AP. [Evaluation of the effectiveness and optimization of the screening diagnostic service for congenital hypothyroidism in Moscow]. Problemy Endokrinologii. 2000;46(5):10-14. [Article in Russian].

17. Rakhimova GN, Zhiemuratova GM. [Evaluation of efficiency of carrying out neonatal screening in RKK, depending on various diagnostic criteria]. Uzbek Medical Journal. 2020;(3):138. [Article in Russian].

18. Yang HH, Qiu L, Zhao JQ, Yang N, Gong LF, Kong YY. [Epidemiologic characteristics and risk factors for congenital hypothyroidism from 1989 to 2014 in Beijing]. Zhonghua Yu Fang Yi Xue Za Zhi. 2016 Aug 6;50(8):728-32. doi: 10.3760/ cma.j.issn.0253-9624.2016.08.011. [Article in Chinese].

19. Nayak P, Moben R, Chako N, Saons ST. Role of technetium scan in diagnosis of congenital hypothyroidism. Inter J Res Med Sci. 2017;5(7):3218-3221.

20. Alimova I, Romankova T. [Register for congenital hypothyroidism and efficiency of neonatal screening in Smolensk region]. Klinicheskaia I Eksperimentalnaia Tiroidologia. 2011;7(1):36-40. [Article in Russian]. 